TAO, Vol. 12, No. 1, 109-135, March 2001

\title{
A Composite Modeling Study of Civil Aircraft Impacts on Ozone and Sulfate over the Taiwan Area
}

\author{
Fujung Tsai $^{1}{ }^{\text {* }}$, Wei-So Sun ${ }^{1}$, and Jen-Ping Chen ${ }^{1}$
}

(Manuscript received 12 January 2001, in final form 22 February 2001)

\begin{abstract}
Aircraft induced ozone and sulfate perturbations calculated from a Lagrangian plume model were composed into a regional distribution to quantify the impacts of aircraft emissions at the international and domestic flight altitudes of about 11.5 and $6.5 \mathrm{~km}$, respectively, over Taiwan. The evolution of pollutant concentrations within a Lagrangian aircraft plume was first calculated with consideration of gas-phase chemistry and mixing of ambient air. Due to reaction with high concentration of aircraft emitted $\mathrm{NO}$, the $\mathrm{O}_{3}$ concentration in fresh aircraft plumes rapidly decreased by more than $15 \mathrm{ppb}$ during the first few hours after emissions. Then, becauseof mixing with the ambient air that contained higher $\mathrm{O}_{3}$ and lower $\mathrm{NO}_{x}$ concentrations, as well as the conversion of $\mathrm{NO}$ into $\mathrm{NO}_{2}$, the $\mathrm{O}_{3}$ concentrations in aged plumes increased and became somewhat (up to $2 \mathrm{ppb}$ ) higher than in the ambient air as the plumes were transported further downwind. The sulfate concentration within the aircraft plumes, on the other hand, was enhanced due to chemical conversion of the emitted $\mathrm{SO}_{2}$. At both the domestic and international flight altitudes, enhancements of up to 10 and 5 ppt greater than in the background were achieved a couple of days after emissions. In the aged and diluted plumes, however, the production of sulfate can be lower than in the ambient because of the lower $O H$ concentration.

The plume results were converted into regional-scale distributions by including all flight frequencies at each international and domestic flight corridor, as well as the probability distribution of the wind speed at the cruising altitudes to account for the advection effect. These composite results indicated that aircraft emissions led to negative perturbation of $\mathrm{O}_{3}$ concentration at and just downwind of the flight corridors, with maximum $\mathrm{O}_{3}$ reduction of about 1 and $4 \%$ at the international and domestic flight altitudes, respectively. The total column (vertically integrated through troposphere) $\mathrm{O}_{3}$, however, was enhanced because the emitted aircraft plumes were transported by various wind speeds and those plumes that stay longer
\end{abstract}

\footnotetext{
${ }^{1}$ Department of Atmospheric Sciences, National Taiwan University, Taipei, Taiwan

* Corresponding author address: Dr. Fujung Tsai, Department of Atmospheric Science, No. 61, Ln. 144, Sec. 4, Keelung Rd., Taipei 106, Taiwan; E-mail: fujung@aerosol.as.ntu.edu.tw
} 
in the domain under low wind speeds had a net production of $\mathrm{O}_{3}$. Since these aged plumes also had much greater volumes, their contributions to column $\mathrm{O}_{3}$ outweighed those from the smaller and more fresh plumes even though the fresh plumes occurred more frequently. Due to the international and domestic aircraft emissions, the tropospheric column $\mathrm{O}_{3}$ can be enhanced by more than 16 and $400 \mathrm{ppt}$, respectively. The sulfate concentrations at the international and domestic flight altitudes were generally enhanced by the aircraft emissions, and the perturbations could be as large as 0.16 and $0.35 \mathrm{ppt}$. The column sulfate perturbations were positive due to international flights, with a maximum reaching about $0.055 \mathrm{ppt}$; whereas the column perturbations from the domestic flights were negative, with a minimum reaching about -2 ppt.

(Key words: Aircraft emissions, Ozone, Sulfate particles, Taipei Flight Information Region)

\section{INTRODUCTION}

As civil aviation activities grow rapidly these days, the potential effects of aircraft emissions on upper tropospheric environment and climate have raised many concerns. The chemicals emitted by aircraft, including $\mathrm{NO}_{x},\left(\mathrm{NO}+\mathrm{NO}_{2}\right), \mathrm{HC}_{\mathrm{x}}$ (hydrocarbons), $\mathrm{CO}, \mathrm{CO}_{2}, \mathrm{SO}_{2}$ and $\mathrm{H}_{2} \mathrm{O}$, are precursors of $\mathrm{O}_{3}$ and aerosol particles in the upper troposphere. Upper tropospheric $\mathrm{O}_{3}$ may increase due to $\mathrm{NO}_{\mathrm{x}}$ and $\mathrm{HC}_{\mathrm{x}}$ enhancement through aircraft emissions. Aircraft emissions of $\mathrm{SO}_{2}$ may be chemically converted into sulfate, which then either forms new particles by binary homogeneous nucleation with water or increases the mass of existing particles by vapor deposition (Arnold et al. 1981; Hagen et al. 1996; Kärcher 1995b, 1996; Schumann et al. 1996). Only about $0.5 \%$ of emitted $\mathrm{SO}_{2}$ are immediately converted into sulfuric acid (Kärcher et al. 1995b), which may serve as nuclei for contrail formation (Schumann et al. 1996; Thornton et al. 1996). The increase of sulfate aerosol may enhance the formation of cirrus clouds (IPCC 1999) or affect $\mathrm{O}_{3}$ production due to sequestering of $\mathrm{NO}_{\mathrm{x}}$ on the particle surface (Anderson et al. 1997). Both $\mathrm{O}_{3}$ and aerosol particles can affect the atmospheric radiation budgets and thus have potential impacts on climate (Charlson et al. 1992).

Over one half of the global aircraft emissions are released at heights between 9 and $13 \mathrm{~km}$, where background chemical concentrations are usually rather low (IPCC 1999), and thus their impacts can be different than in the lower troposphere. The residence times of chemical species at these altitudes are usually longer than in the lower troposphere where the removal processes are more efficient. Therefore, the impacts of aircraft emissions can persist for a long period of time and over extended regions. Several European and American research efforts have been carried out by applying regional- or global-scale modeling to understand aircraft impacts on $\mathrm{NO}_{x}, \mathrm{O}_{3}, \mathrm{SO}_{2}$ and sulfate aerosol (e.g., Beck 1990; Kasibhatla 1993; Johnson and Stevenson 1996; Brasseur et al. 1996; Schumann 1997; Meijer et al. 2000). These modeling studies showed that aircraft-induced $\mathrm{NO}_{x}$ and $\mathrm{O}_{3}$ perturbations are about 4 to $53 \%$ and 1 to 
$10 \%$, respectively, over the northern mid-latitudes upper troposphere. Pitari et al. (1993) also indicated that aircraft induced perturbations of $\mathrm{SO}_{2}$ concentration and sulfate aerosol surface area are about $100 \%$ and $60 \%$, respectively, around the $100 \mathrm{hPa}$ level in the northern midlatitudes.

Aircraft emissions over Taiwan have also raised local interest and their impacts are under investigation. Lin et al. (2001) estimated the aircraft-emitted chemicals from commercial jet, cargo jet and propeller aircraft over the Taipei Flight Information Region (hereafter, Taipei FIR). Their detailed emission inventory can be applied to a regional model to quantitatively estimate the aircraft impacts over the Taiwan area. However, as pointed out by Petry et al. (1998) as well as Tsai and Walcek (2001), most regional- and global-scale modeling studies overestimate aircraft impacts due to an artificial dilution of plume-scale emissions into larger model grids and neglect the nonlinearity of $\mathrm{NO}_{x}$ and $\mathrm{O}_{3}$ relationship. To avoid such errors, we estimated the regional impacts of aircraft emissions in three steps. First, a Lagrangian plume model was applied to simulate the evolution of chemical concentrations in the aircraft plumes at the international and domestic flight altitudes. Particular attention was paid to the perturbations of $\mathrm{O}_{3}$ and sulfate concentration due to aircraft emissions. Then, following the approach of Chen et al. (2001), the temporal evolution of chemical concentrations was converted into a spatial distribution by incorporating the wind speed distribution at the cruising altitudes. Finally, the spatial distribution of a single plume was mapped onto the flight routes for all flights to form a composite regional result of aircraft impacts over the Taiwan area. The impacts of aircraft emission over the Taiwan areas, where the average residence time of air ranges from about several hours to less than a day, can be quantified through this composite calculation.

\section{LAGRANGIAN PLUME MODEL}

A Lagrangian plume model was applied to simulate the chemical evolution of a unit section of aircraft plume as it expanded with time while following wind field in the upper troposphere. At the flight altitudes where strong westerly wind prevails, the plume grows with time by turbulent diffusion and deforms because of the vertical wind shear. Vertical wind shear at the flight altitudes can be divided into two components: one perpendicular to the plume body (x-component) and the other along the plume body (y-component). The $\mathrm{x}$-component wind shear stretches the plume (Fig. 1), whereas the y-component wind shear does not affect the plume growth rate. The plume dispersion rate increases due to the $\mathrm{x}$-component wind shear deformation. In this shear environment, the standard deviation in the horizontal $\left(\sigma_{x}\right)$, vertical $\left(\sigma_{z}\right)$, and shear axis $\left(\sigma_{s}\right)$ directions of the aircraft plumes are given as follows (Tsai and Walcek 2001, this issue):

$$
\begin{gathered}
\sigma_{x}^{2}=\frac{2}{3}\left[\frac{\partial u}{\partial z}\right]^{2} K_{z} t^{3}+2 K_{x} t+\left[\frac{\partial u}{\partial z} \sigma_{z 0} t\right]^{2}+\sigma_{x 0}^{2} \\
\sigma_{s}^{2}=\frac{\partial u}{\partial z} K_{z} t^{2}+\frac{\partial u}{\partial z} \sigma_{z 0}^{2} t
\end{gathered}
$$


Fig. 1. Schematic diagram of the cross section of an aircraft plume after it was emitted into the free troposphere. The aircraft plume is deformed due to vertical wind shear as it grows with time at the flight altitude. The $\mathrm{u}_{1}, \mathrm{u}_{2}$, and $\mathrm{u}_{3}$ are horizontal wind speed at different heights that are perpendicular to the plume body.

$$
\sigma_{z}^{2}=2 K_{z} t+\sigma_{z 0}^{2},
$$

where the $\sigma_{x 0}$ and $\sigma_{z 0}$ are the initial horizontal and vertical standard deviations, respectively; $\partial u / \partial z$ is the vertical wind shear perpendicular to the plume axis; $K_{\mathrm{x}}$ and $K_{\mathrm{z}}$ are the horizontal and vertical diffusion coefficients, respectively; and $t$ is the time after emission. In calculating the plume growth rate, as described by Eqs. (1) (3), pollutants are confined to a certain volume of the growing plume in which the pollutants are assumed to be uniformly mixed. The defined plume boundary contains a unit length of aircraft plume with a cross section area described as follows,

$$
\mathrm{A}=1.21 \pi \sqrt{\sigma_{z}^{2} \sigma_{x}^{2}-\sigma_{s}^{4}},
$$

which increases with time as the standard deviations $(\sigma)$ expand. The 1.21 factor arises from the conversion of an ideal Gaussian to the best-fitting well-mixed concentration profile.

As aircraft plume grows with time, it also mixes with the ambient air. Thus, in calculating the concentration tendency $(\partial C / \partial t)$ of reactive species within aircraft plumes, one needs to determine the entrainment rate of the ambient air that mixes into the plume and changes the pollutant concentrations. In addition, there are production and loss rates due to chemical reactions for both the ambient air and the plume. The tendency equations for this entraining plume are thus described as follows,

$$
\begin{gathered}
\frac{\partial C_{p}}{\partial t}=P_{p}-L_{p}+\left(C_{e}-C_{p}\right)\left(\frac{d V}{d t}\right)\left(\frac{1}{V}\right), \\
\frac{\partial C_{e}}{\partial t}=P_{e}-L_{e},
\end{gathered}
$$


where $C$ is the concentration of chemical species, $V$ is the plume volume, $P$ and $L$ are chemical production and loss rates, and subscripts $p$ and $e$ represent the plume and ambient environment, respectively. The last term in (5) represents the dilution effect due to entrainment of ambient air. The concentrations of the reactive chemicals in the growing aircraft plume therefore change with time due to both the chemical productions and loss and entrainment of ambient air, but the latter need not be considered for the ambient air as indicated in Eq. (6).

Table I lists the meteorological conditions and aircraft plume parameters used in the Lagrangian plume model. The atmospheric pressure, temperature and vertical wind shear in Table I were obtained from a 5-year averaged Ban-Chiao sounding data. For water vapor, we used the standard subtropical conditions obtained from Ellingson et al. (1991). The simulations start at 1000 seconds after the plume exits the engine nozzle, assuming that the plume at this time had passed the vortex and jet regime (Hoshizaki 1975; Kärcher 1995a). The initial horizontal and vertical plume sizes in Table I were obtained by assuming an initially circular plume with cross-section area of $10^{5} \mathrm{~m}^{2}$, which were derived from the results of Kärcher (1995a) and $\mathrm{Yu}$ and Turco (1997) for aircraft plumes at 1000 seconds after emission. For the vertical and horizontal diffusion coefficients, we followed the study of Hanna et al. (1982), Liu et al. (1984) and Schumann et al. (1995).

The plume model integrated the Stockwell chemical mechanism (Stockwell et al. 1990) forward in time. The gas phase chemistry contains 157 reactions among 63 species, including 42 organics. The 21 photolysis rate coefficients needed were derived from a radiative transfer model and are functions of time, latitude and altitude. Diurnal varying photolysis rates typical of fall at middle and upper troposphere $25^{\circ} \mathrm{N}$ conditions were used.

Tables II and III show the initial ambient and plume chemical concentrations of some major species applied to the Lagrangian plume model. The initial ambient concentrations

Table I. Meteorological conditions and plume parameters used in Lagrangian plume model.

\begin{tabular}{|c|c|c|}
\hline Temperature" $(\mathrm{K})$ & $\begin{array}{l}6 \mathrm{~km} \\
263\end{array}$ & $\begin{array}{c}11 \mathrm{~km} \\
228 \\
\end{array}$ \\
\hline Pressure (PN) & 460 & $20 \pi$ \\
\hline Walter vuporh (pprn) & 1485 & 64 \\
\hline Verlicsal wind she:ar" $\left(\mathrm{s}^{-1}\right)$ & $1.1 \times 10^{3}$ & $2.6 \times 10^{5}$ \\
\hline Plume infial horizontal dispersion $\left(\mathrm{s}_{\mathrm{v}}\right)(\mathrm{m})$ & 178.5 & 178.5 \\
\hline Plume initial vertical dispersion $\left(\sigma_{\text {nin }}\right)(\mathrm{m})$ & 178.5 & 178.5 \\
\hline Vertical ditfision coefficient $(\mathrm{K})\left(\mathrm{m}^{2} \mathrm{~s}^{-1}\right)$ & 10 & $5 \times 10^{-1}$ \\
\hline I lorizuntal difisisisn coelTicient' $\left(\mathrm{K}_{x}\right)\left(\mathrm{ml}^{2} \mathrm{~s}^{-1}\right)$ & 10 & 10 \\
\hline Sirsulation slart limet' (hour o $\Gamma$ the day) & $\begin{array}{c}6 \cdot 9 \cdot 12 \cdot 15 \\
18 \cdot 21\end{array}$ & $\begin{array}{r}6 \cdot 9 \cdot 12 \cdot 15 \\
18 \cdot 21 \cdot 23\end{array}$ \\
\hline
\end{tabular}

4: oblaised from Baл-Chiso sounding

b: obtained tiom E'llingson et al., (1991)

c; derived or obtained from Hamna et al, (1982); Lim et al, (1984); Karcher (1995);

Sthumerm el ul., (1995); Yu und Turoo (1997)

d: every three hour duritg the aircralt llying time of the day 
shown in Table II were obtained from observations over the western Pacific Ocean or background measurements (Cuong et al. 1973; Georgii 1978; Singh et al. 1996; Talbot et al. 1996; Simpson et al. 2000). For aircraft plumes, we derived the initial chemical concentrations based on the aircraft emission indices of the Taiwan area (Lin et al. 2001) and fuel to air mixing ratio of $1 \mathrm{~kg}$ to $14 \mathrm{~kg}$ (IPCC 1999). This gave us the chemical concentrations of $\mathrm{SO}_{2}$, $\mathrm{CO}_{2}, \mathrm{NO}_{\mathrm{x}}$ and $\mathrm{H}_{2} \mathrm{O}$ in the aircraft plume when it just exited from the engine nozzle. According to the studies of Kärcher (1995a) and Yu and Turco (1997), aircraft plume is diluted by about 7700 times at about 1000 seconds after emissions. By further applying this dilution factor, we obtained the initial chemical concentrations of the emitted species for the aircraft plume at that time (see Table III). The initial concentrations obtained this way agree well with those used in previous studies (Zhao and Turco 1995; Kärcher 1995a; Kärcher et al. 1996; Hayman and Markiewicz 1996; Ford et al. 1996). The aircraft also emit many species of hydrocarbons. We apportioned the initial hydrocarbon concentrations to several major species according to Beck et al. (1990). The initial concentrations for non-emitted chemical species were set to be the same for both the aircraft plume and the ambient air.

The residence time of the aircraft plumes within the interested area can be as short as a few hours. Within this short time frame, the simulation results will be affected by the selection of the starting time of the day due to different actinic flux and thus photolysis rates experi-

Table II. The initial ambient concentrations (ppt) used for the international and domestic flight altitudes of the Lagrangian plume model.

\begin{tabular}{|c|c|c|c|}
\hline specics & & domestic & international \\
\hline$-\mathrm{sO}_{2}$ & & 386 & 130 \\
\hline $\mathrm{NO}_{x}$ & & 47 & 90 \\
\hline 0 & & 36000 & 41000 \\
\hline $1 \overrightarrow{\mathrm{N}} \mathrm{O}_{3}$ & & 68 & 31 \\
\hline PAN & & 51 & 78 \\
\hline $\mathrm{HNG}$ & & 35 & 28 \\
\hline $\mathrm{HCHO}$ & & 123 & 46 \\
\hline 11,0 & & 277 & 102 \\
\hline$\infty$ & & 84 & 91 \\
\hline$\overline{C H}_{4}$ & & 1827060 & 1827000 \\
\hline
\end{tabular}

Table III. Initial chemical concentrations (ppb) for the aircraft plumes used in the Lagrangian plume model.

\begin{tabular}{|c|c|c|}
\hline species & domestic & international \\
\hline $\mathrm{SO}_{2}$ & 3.5 & 3.25 \\
\hline $\mathrm{NO}_{\mathrm{X}}$ & 129.2 & 129.3 \\
\hline $\mathrm{CO}$ & 99.2 & 106 \\
\hline $\mathrm{HC}_{\mathrm{X}}$ & 2 & 2 \\
\hline
\end{tabular}


enced by the plume during the period. Since the aircraft flights over the Taipei FIR only operate during a certain period of the day, it is possible to categorize the flights according to the diurnal flight patterns given by Lin et al. (2001) and average the results calculated from each category of the flights. So, we classified the flights into several groups, each within a 3hour interval, starting from $6 \mathrm{AM}$ and ending at $21 \mathrm{PM}$ for domestic flights, but ending at 23 PM for international flights (see Table I). Simulations were performed for each group with different starting times and the results obtained from each group were then weighted by the flight frequency within that time interval (Table IV) to give the averaged results. The simulations were carried out for 12 days as we assumed that the $\mathrm{O}_{3}$ residence time in the upper troposphere is approximately within such a time frame, the same as that discussed in Tsai and Walcek (2001).

Table IV. Ratios of flight frequency during every 3-hour interval at the international and domestic flight altitudes over the Taipei Flight Information Region.

\begin{tabular}{|c|c|c|c|c|c|c|c|}
\hline Hour & 6 & 9 & 12 & 15 & 18 & 21 & 23 \\
\hline International & 0.0461 & 0.1843 & 0.1653 & 0.1761 & 0.1707 & 0.1870 & 0.0705 \\
\hline Domestic & 0.0597 & 0.2208 & 0.2052 & 0.2338 & 0.1766 & 0.1039 & 0.0000 \\
\hline
\end{tabular}

\section{PLUME SCALE RESULTS}

In this section, the time variation of calculated plume-scale $\mathrm{O}_{3}$, sulfate and related concentrations within a single aircraft plume at both the international and domestic flight corridors are discussed. The $\mathrm{NO}_{x}, \mathrm{O}_{3}, \mathrm{SO}_{2}$, and sulfate concentrations discussed below are averaged concentrations from different initial times with flight-frequency weighting as discussed in Section 2. The heights of the aircraft plume core are set at 11.5 and $6.5 \mathrm{~km}$, which represent the height of peak flight frequency of the international and domestic flights according Lin et al. (2001).

Figure 2 shows the time variation of $\mathrm{O}_{3}$ concentrations in both the ambient air and aircraft plumes at the international and domestic flight altitudes. Also shown is the time evolution of the relative plume growth ratio (ratio of cross-section area to its initial area), which is equivalent to the dilution efficiency due to entrainment of ambient air. From this relative growth ratio one can see that the plume expands rather rapidly with time, reaching several thousands times its initial size (about $1.2 \times 10^{5} \mathrm{~m}^{2}$ near the engine nozzle) a few days after emissions. The plume growth rate is greater at the domestic flight altitudes (Fig. 2b) than at the international flight altitudes (Fig. 2a), because the vertical diffusion rate $\left(\mathrm{K}_{\mathrm{z}}\right.$ in Table $\left.\mathrm{I}\right)$ is much larger. The ambient $\mathrm{O}_{3}$ concentrations are initially about 41 and $36 \mathrm{ppb}$ at the international and domestic flight altitudes. Since the initial conditions were chosen to be near a chemical steady state, the ambient $\mathrm{O}_{3}$ concentration varies slightly with time. In the aircraft plume, however, the $\mathrm{O}_{3}$ concentration dropped almost immediately by more than $15 \mathrm{ppb}$ at both altitudes. It then increases rapidly to the ambient level and, at the international flight altitudes, even becomes a few ppb higher than in the ambient air by the end of the second day. The excess $\mathrm{O}_{3}$ concentra- 
(a)

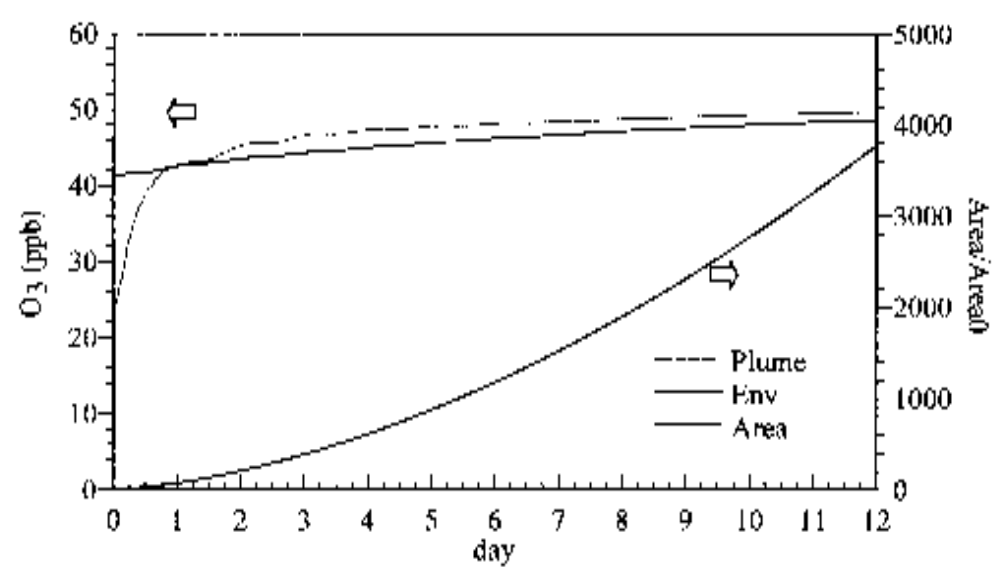

(b)

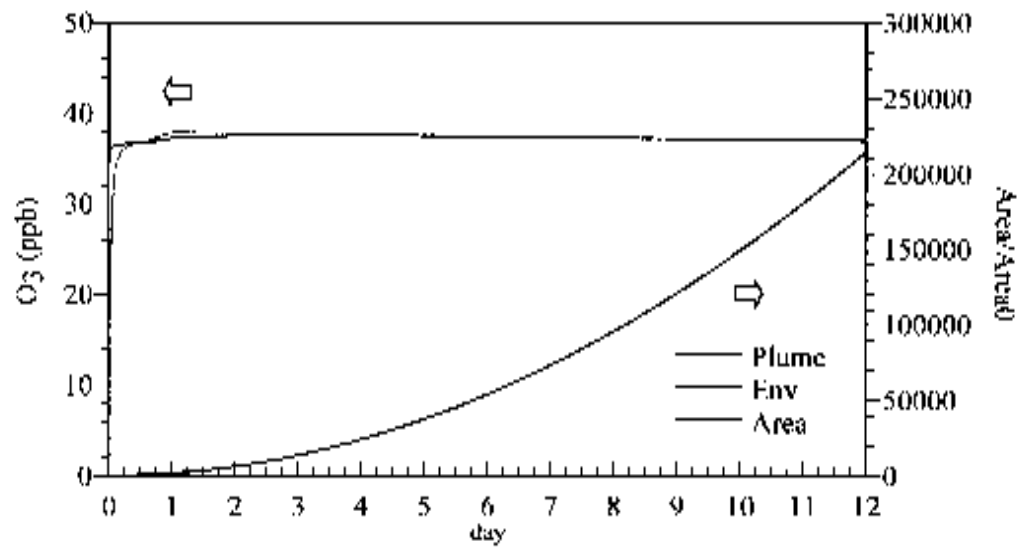

Fig. 2. Time evolution of simulated $\mathrm{O}_{3}$ concentrations in ambient environment (dotted line) and aircraft plumes (solid line), and the relative growth rate of plume cross-section area (dotted-dash line) at (a) international and (b) domestic flight altitudes over Taiwan.

tion within aircraft plume then gradually dilutes toward the end of the simulation. The rapid decrease of the $\mathrm{O}_{3}$ concentration immediately after the emission results from the reaction with high concentration of NO that is directly emitted by the aircraft. Then, as the aircraft plume expands with time, ambient air with higher $\mathrm{O}_{3}$ and lower $\mathrm{NO}_{x}$ concentrations is gradually mixed in. In addition, $\mathrm{O}_{3}$ is quickly re-generated because most of the original $\mathrm{NO}$ in the plume has been converted into $\mathrm{NO}_{2}$ in the downwind area. As the $\mathrm{NO}_{2}$-related reactions keep generating $\mathrm{O}_{3}$, the plume $\mathrm{O}_{3}$ concentration eventually becomes higher than in the ambient air 1 to 2 days after emissions. The perturbation of the plume $\mathrm{O}_{3}$ concentration is more obvious in Fig. $2 a$ than in Fig. $2 b$ because the aircraft plume growth rate (i.e., dilution rate) is faster in the domestic flight corridors, resulting in a smaller increase of $\mathrm{O}_{3}$ concentration during the later 
stages. Note that the aircraft-emitted $\mathrm{NO}_{\mathrm{x}}$ is still generating $\mathrm{O}_{3}$ toward the end of the simulation. But, because of the strong dilution effect, the plume $\mathrm{O}_{3}$ concentration remains roughly unchanged with time or even slightly decreases with time. Some diurnal variations of $\mathrm{O}_{3}$ concentration in the plume can also be seen during the first few days of simulation. This is because $\mathrm{O}_{3}$ is photochemically produced during daytime and the concentration is reduced at night by reaction with NO. Mixing with the ambient air also reduces the $\mathrm{O}_{3}$ concentration of the aircraft plume when the concentration is greater than in the ambient air. In the ambient air or in aged plume, however, the diurnal variation is not obvious due to their low $\mathrm{NO}_{\mathrm{x}}$ concentrations.

Figure 3 shows the time evolution of $\mathrm{NO}_{x}$ concentrations in the ambient air and aircraft plume at the international (Fig. 3a) and domestic (Fig. 3b) flight altitudes. The ambient $\mathrm{NO}_{\mathrm{x}}$ concentrations at both the international and the domestic flight altitudes decrease slightly with time from the initial concentrations because $\mathrm{NO}_{\mathrm{x}}$ is constantly converted into other nitrogen species, mostly nitric acid. The $\mathrm{NO}_{\mathrm{x}}$ concentrations within the aircraft plume, on the other hand, decrease rapidly from about $130 \mathrm{ppb}$ to near the ambient level at both the international and domestic flight altitudes. These high concentrations of $\mathrm{NO}_{\mathrm{x}}$ (mostly $\mathrm{NO}$ ) during the initial stage result in a rapid decrease of the $\mathrm{O}_{3}$ concentrations within the aircraft plume due to reaction with $\mathrm{NO}$ in the initial stage, although $\mathrm{NO}$ quickly reaches chemical equilibrium with $\mathrm{NO}_{2}$ as aircraft plumes move downwind. In additional to chemical conversion, the $\mathrm{NO}_{\mathrm{x}}$ concentrations in the aircraft plume decrease mainly because of the dilution effect. The rapid mixingexpansion of the aircraft plume leads to a fast dilution of the chemical species and this effect is more obvious for the domestic flight plumes due to a more rapid plume dispersion rate.

The time evolution of $\mathrm{HO}$ concentrations in the ambient air and aircraft plume at both flight altitudes are shown in Fig. 4. Figure 4 shows the diurnal fluctuation of HO concentration as $\mathrm{HO}$ mainly comes from photochemical production during the daytime and is destroyed through chemical reactions at night. Because the HO concentrations in Fig. 4 were averaged from simulations starting at different local times according to the flight schedules as discussed in Section 2, the peak concentrations during the daytime are bimodal. Without the time averaging, the time variation of the $\mathrm{HO}$ concentrations in both aircraft plume and the ambient air starting from any time instant only shows a single peak. Figure 4 shows that HO concentrations within the plume are greater than in the ambient air during the first few days due to the enhanced $\mathrm{NO}_{\mathrm{x}}$ concentrations in the aircraft plume. The $\mathrm{HO}$ concentrations in the aircraft plumes are double that in the ambient air, and the concentrations are higher in the domestic flight altitudes (Fig. 4b) than in the international flight altitudes (Fig. 4a). As the $\mathrm{NO}_{\mathrm{x}}$ concentrations within the aircraft plumes dilute with time and other aircraft emitted species induce a fast depletion of $\mathrm{HO}$ through chemical reactions, the $\mathrm{HO}$ concentrations within the aircraft plume decrease and eventually reach a value slightly lower than in the ambient air.

The time evolutions of $\mathrm{SO}_{2}$ concentration in the ambient air and within the aircraft plumes at the international and domestic flights are shown in Figs. 5a and 5b, respectively. The ambient $\mathrm{SO}_{2}$ concentrations slightly decrease with time due to chemical conversion into sulfate by reaction with $\mathrm{HO}$ radicals. On the other hand, the $\mathrm{SO}_{2}$ concentrations within the plume decrease rapidly from more than $3 \mathrm{ppb}$ to near the ambient level within one or two days, mainly as a result of dilution by the entrained ambient air. Figure $5 \mathrm{~b}$ shows a more rapid decrease of 
(a)

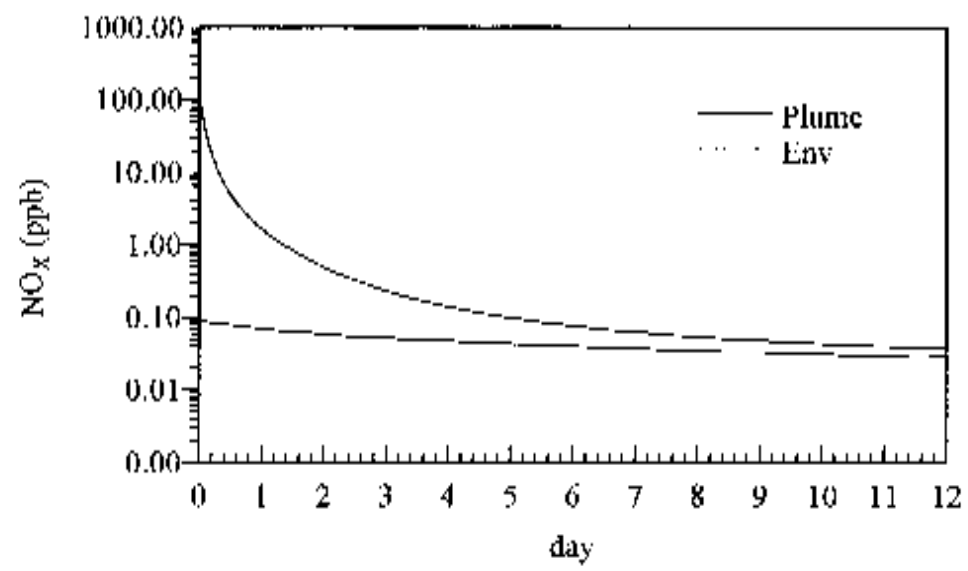

(b)

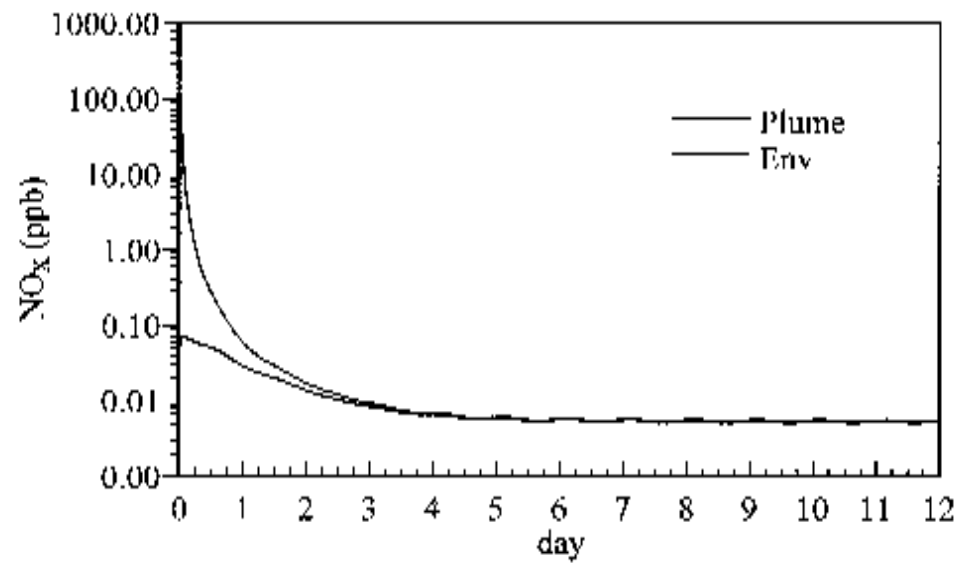

Fig. 3. Time evolution of simulated $\mathrm{NO}_{\mathrm{x}}$ concentrations in ambient environment (dotted line) and aircraft plumes (solid line) at the (a) international and (b) domestic flight altitudes over Taiwan.

plume $\mathrm{SO}_{2}$ concentration than in Fig. 5a, again as a result of faster dilution of aircraft plumes at those altitudes. Since we only considered gas phase reactions in this study, the chemical loss of $\mathrm{SO}_{2}$ comes from reaction with $\mathrm{HO}$ radical only. Because $\mathrm{HO}$ concentration within the plume is higher than in the ambient air during the first few days, by reacting with the more concentrated $\mathrm{HO}$, the $\mathrm{SO}_{2}$ concentration in the plume after the second day becomes slightly lower than in the ambient air, and the effect is more obvious at the international flight altitudes.

Figure 6 shows the time variations of enhanced sulfate concentration (i.e., sulfate concentration minus its initial value) in the plume and ambient air. As gas phase sulfate concentration is usually low and vary with time and space in the atmosphere, sulfate enhancement instead of its concentration is presented here to avoid the difficulty of choosing an initial value. The 
(a)

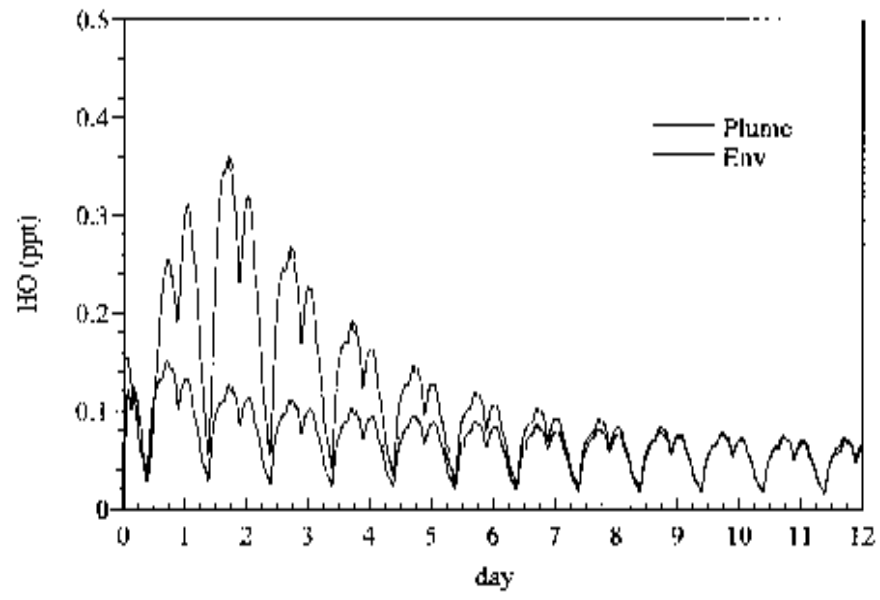

(b)

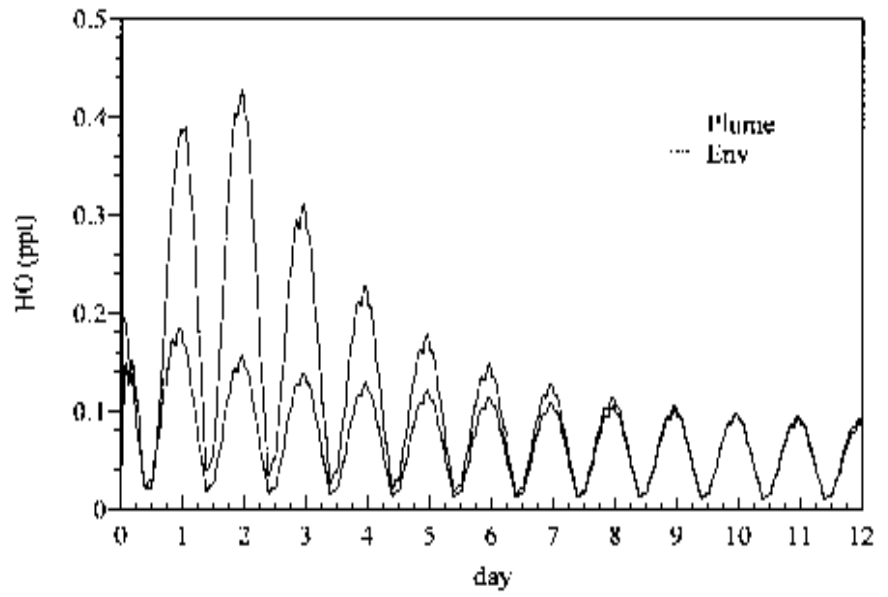

Fig. 4. Same as in Fig. 3, but for HO concentrations at the (a) international and (b) domestic flight altitudes.

ambient sulfate concentrations increase with time at both the international and domestic altitudes due to reaction of $\mathrm{SO}_{2}$ with $\mathrm{HO}$ (no other source or sink of sulfate is considered in this study). Within the aircraft plume, the sulfate concentration increases more rapidly during the first three days than later, with a maximum increase of concentration up to 10 and $5 \mathrm{ppt}$ at the international and domestic flight corridors, respectively. The rapid sulfate production results from reaction of the high concentration of aircraft emitted $\mathrm{SO}_{2}$ with $\mathrm{HO}$ radicals. The production then slows down due to the dilution effect as well as the depletion of $\mathrm{SO}_{2}$ inside the aircraft plume. For aged plumes, the $\mathrm{HO}$ concentration becomes slightly lower in the plume than in the ambient air, leading to a smaller sulfate production in the aircraft plume than in the ambient air. Thus, the sulfate concentration at the domestic flight altitudes is lower in the 
(a)

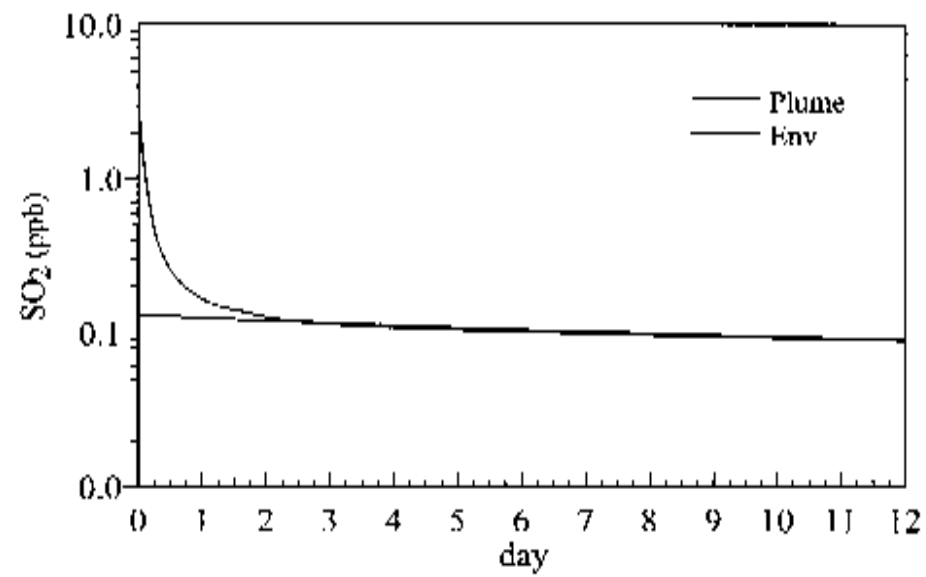

(b)

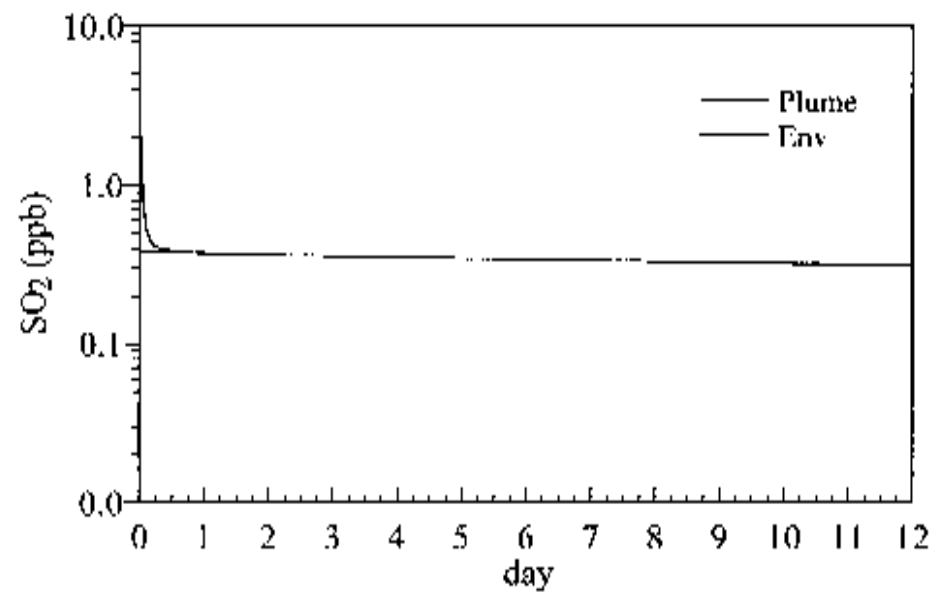

Fig. 5. Same as in Fig. 3, but for $\mathrm{SO}_{2}$ concentrations at the (a) international and (b) domestic flight altitudes.

aircraft plume than in the ambient air during the last several days of simulation. Also in Fig. 6, one can see the diurnal fluctuation of sulfate. As HO can only be photochemically produced, $\mathrm{SO}_{2}$ is converted into sulfate only during daytime in both the plume and the ambient air. At night, the sulfate concentrations within the aircraft plume decrease as a result of dilution effect, while the concentration in the ambient air remains almost constant.

\section{COMPOSITE REGIONAL RESULTS}

The regional results of aircraft impacts are obtained by mapping individual plume results onto flight routes and their downwind regions for all flights over the Taipei FIR. This is first 
(a)

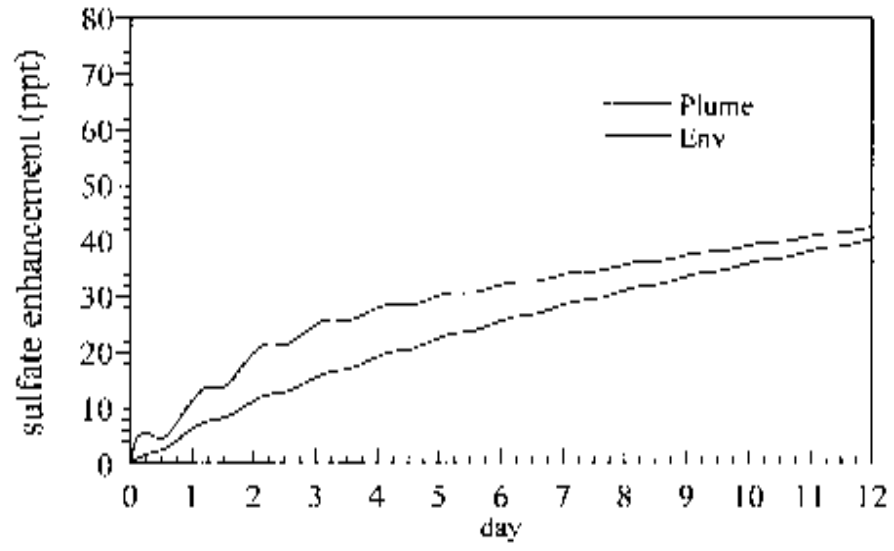

(b)

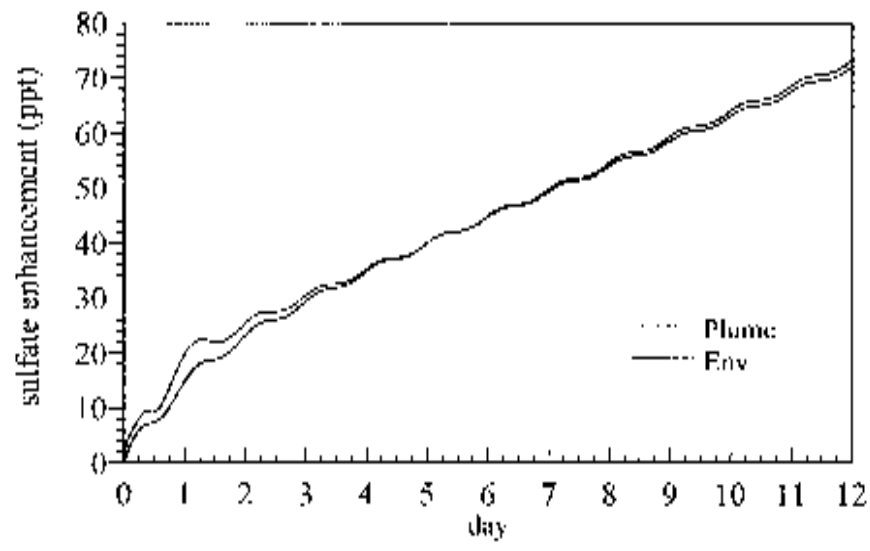

Fig. 6. Same as in Fig. 3, but for sulfate enhancement at the (a) international and (b) domestic flight altitudes.

done by converting the temporal distribution of chemical species calculated from the plume model into a spatial distribution. As aircraft plumes evolve with time, they are also transported away from the flight route by the wind fields. If the wind speed is a constant, one only has to multiply the traveling time of the aircraft plume with the wind speed to obtain the spatial distribution of the plume. However, the wind speeds at both the international and domestic flight corridors have significant temporal variations. Therefore, following the approach of Chen et al. (2001), we obtained the spatial variation of aircraft plume by applying the annual probability distribution of wind speeds to the time variation of chemical species at the international and domestic flight altitudes according to the 1997 Ban-Chiao sounding data. The analysis of the sounding data shows that over $90 \%$ of the winds at the international and domestic flight altitudes are zonal winds. Therefore, only the zonal winds were considered here to simplify the calculation. Figure 7 shows the probability distribution of the zonal wind fre- 
quency at the international and domestic flight altitudes. It is obvious that these zonal winds are mostly eastward (positive wind speed in Fig. 7), with maximum frequency at about $42 \mathrm{~m}$ $\mathrm{s}^{-1}$ and $17 \mathrm{~m} \mathrm{~s}^{-1}$ at the international and domestic flight altitudes, respectively. By applying these wind distributions, we converted the time variations of chemical species shown in Figs. 2 and 6 into the spatial distributions shown in Figs. 8 and 9.

Figures 8 and 9 are derived due to single aircraft emissions. To obtain a regional result, one then needs to know the exact location and flight frequency of each flight route over the Taipei FIR. The distribution of the flight routes can be found in Lin et al. (2001). The flight

(a)

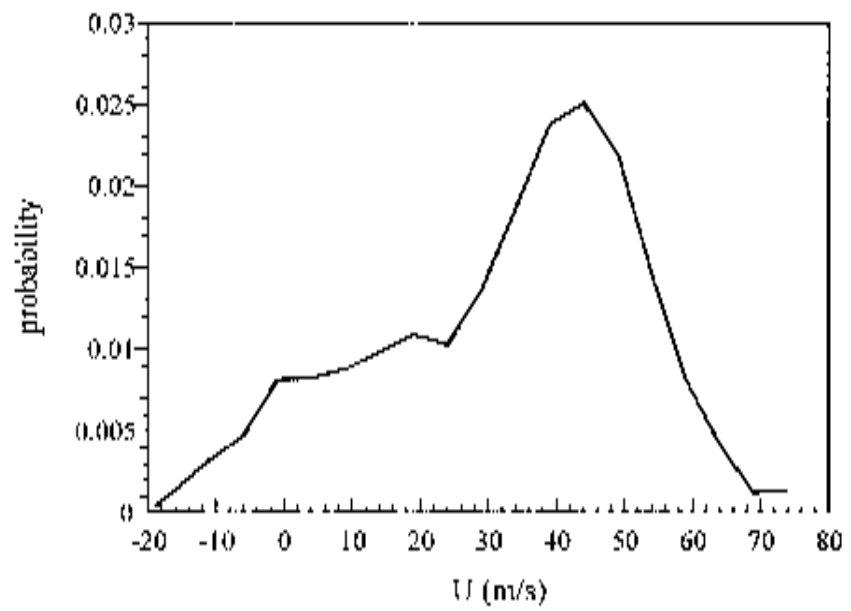

(b)

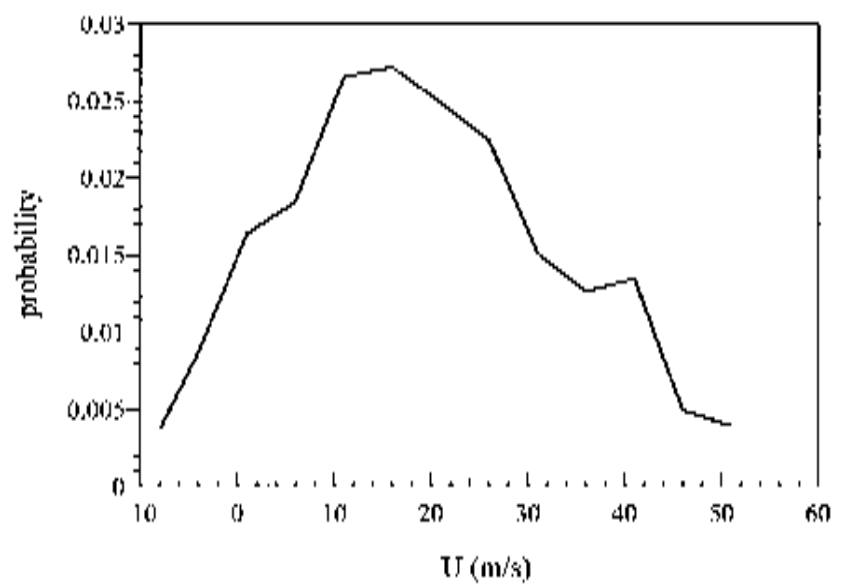

Fig. 7. Probability distribution of the zonal wind speed at the (a) international $(\sim 11.5 \mathrm{~km})$ and (b) domestic $(\sim 6.5 \mathrm{~km})$ flight altitudes over Taiwan. Positive wind speeds are westerlies (move eastward) and negative wind speeds are easterlies (move westward). 
(a)

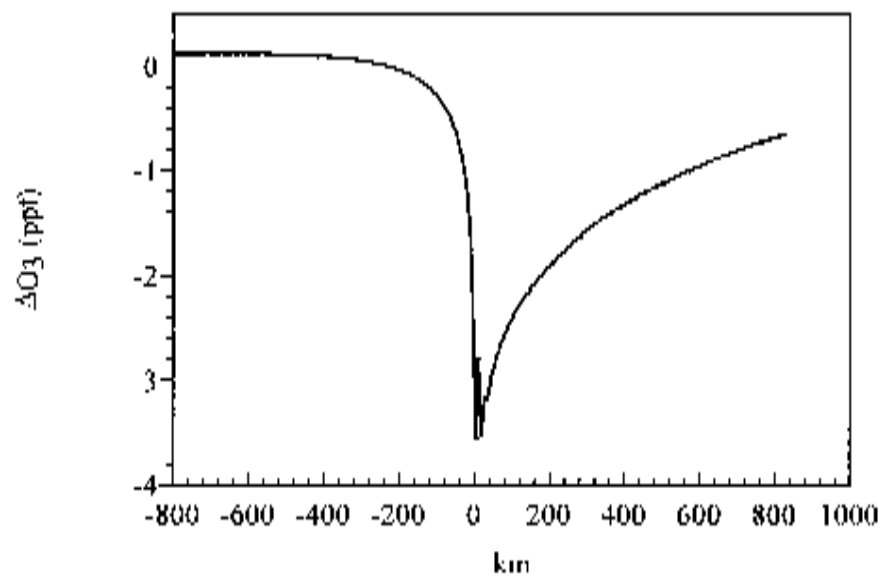

(b)

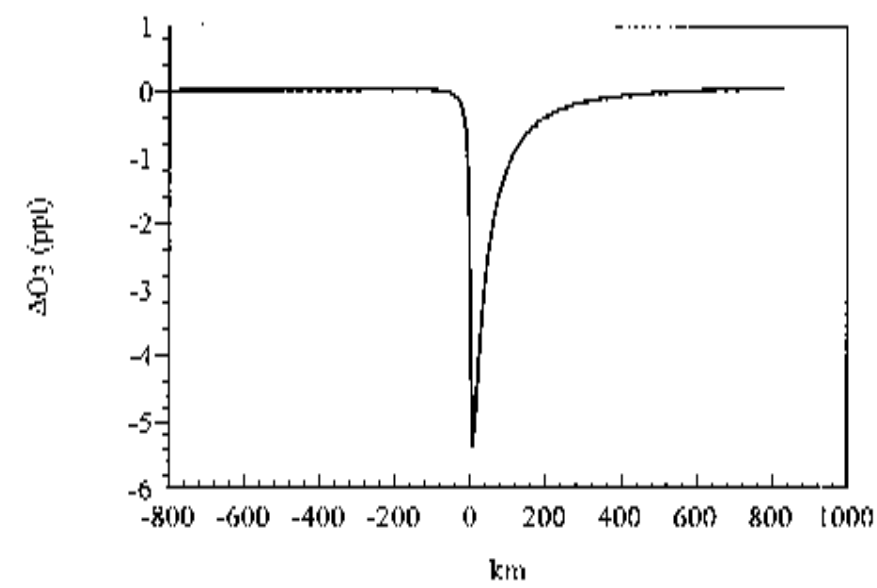

Fig. 8. Spatial variation of $\mathrm{O}_{3}$ perturbations due to single aircraft plume emissions along the (a) international and (b) domestic flight routes.

frequencies and their relative percentages between way-points at the international flight corridors are given in Table $\mathrm{V}$, while the same information between two airports of the domestic flights are given in Table VI. Table V shows that the busiest routes of the international flights are along ELA-APU (between Hong-Kong and Taipei) and APU-BLN (between Taipei and Japan or North America), each account for 24.8 and $22.2 \%$ of the total flights. For the domestic flights, over $80 \%$ of the air traffic occurs along the western coast of Taiwan.

\subsection{Spatial Variations due to Single Aircraft Emissions}

Figures 8 and 9 show the spatial distributions of $\mathrm{O}_{3}$ and sulfate perturbations due to single 
(a)

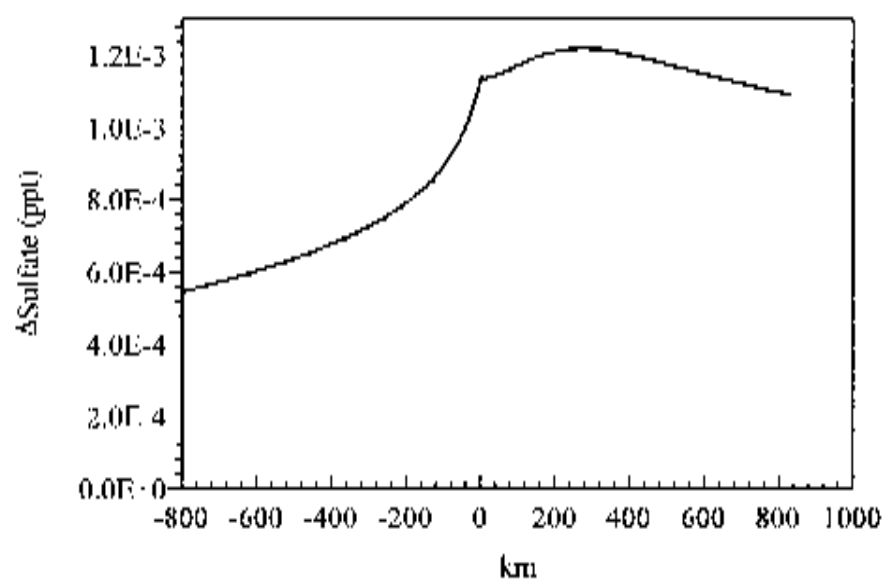

(b)

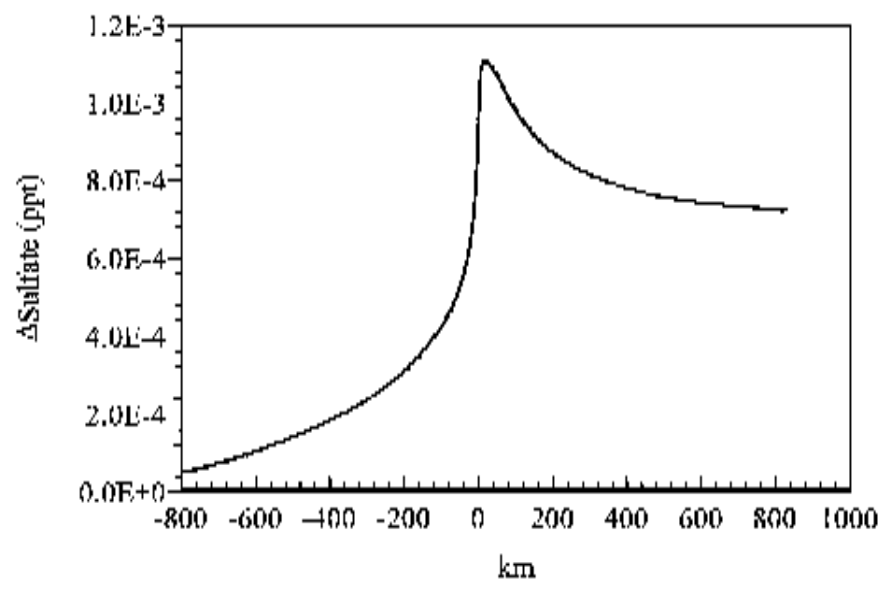

Fig. 9. Same as in Fig. 7, but for sulfate concentrations.

aircraft emissions. The origin of the horizontal distance corresponds to the flight route, and extending eastward or westward by about $800 \mathrm{~km}$ to cover the domain distance of the Taipei FIR. Under mean westerly wind speeds at the international and domestic flight altitudes, it normally takes about 7 and 12 hours for the westerly wind to enter from the west and exit the eastern boundary of the domain. On the other hand, under the mean easterly wind, it takes about one and two days for the air to travel across the domain. Therefore, the $800 \mathrm{~km}$ range eastward from the origin of Fig. 8 (Fig. 9) roughly corresponds to the first 7 and 12 hours' results in Fig. 2 (Fig. 6) for the international and domestic corridors, respectively; whereas, the same range westward from the origin corresponds to about 1 and 2 days' results.

Figure 8 shows the spatial variation of $\mathrm{O}_{3}$ perturbations resulting from single aircraft emissions. The values of $\mathrm{O}_{3}$ perturbation shown in this figure are much lower than those from temporal variations shown in Fig. 2, because the effects of a single aircraft were spread out 
Table V. Mean flight frequencies and their relative percentages between waypoints at the international flight altitudes over the Taipei Flight Information Region in 1997.

\begin{tabular}{|c|c|c|}
\hline \multirow{3}{*}{$\begin{array}{l}\text { Air'Way } \\
\Gamma I A-A \Gamma L \\
\text { APT } I-S M I\end{array}$} & \multirow{2}{*}{$\frac{\text { Froqueney (flights/duy) }}{147}$} & Perceril $(\%)$ \\
\hline & & 24.8 \\
\hline & 35 & 5,9 \\
\hline APTJ-BT NN & 132 & 22.2 \\
\hline A PI_-ATMO & 28 & 4.7 \\
\hline APLI-SKU & 11 & 1.9 \\
\hline$A P^{3} U=\overline{D O R}$ & 37 & 6.3 \\
\hline$\Gamma \mathrm{I} A-\mathrm{I}[\mathrm{CN}$ & 50 & 9.5 \\
\hline HCNAGR & 32 & 5,4 \\
\hline KPL.-HCN & 61 & 10.3 \\
\hline l'KR-HCN & 53 & 9 \\
\hline tonat & 592 & 100 \\
\hline
\end{tabular}

Table VI. Mean flights frequencies and their relative percentages between airports at the domestic flight altitudes over the Taipei Flight Information Region in 1997.

\begin{tabular}{|c|c|c|}
\hline$\Delta \mathrm{ir}-W_{\mathrm{a} y}$ & Froplucney (Mightw/duy) & Percerit $(\%)$ \\
\hline Taipej-C.K.s' & 5014 & 19.4 \\
\hline CK.S-Taichung & 449 & 17.3 \\
\hline Taichung-Chisyil & 387 & 15 \\
\hline Chiнyi-Tuпnл" & 345 & 13.3 \\
\hline Iainan-Kanhoiung' & 335 & 13 \\
\hline Kaohginne-l'ingtumg' & 15 & 0.6 \\
\hline Katulisiung-Lan Yu & 4 & 0.1 \\
\hline C.K.5-Makuth & \multirow{3}{*}{$\begin{array}{l}49 \\
58 \\
128\end{array}$} & \multirow{2}{*}{$\frac{1.9}{2.2}$} \\
\hline Makung-Chin Merl & & \\
\hline Iainan-Makung & & 5 \\
\hline l'ainan-Chimei & 9 & \multirow{2}{*}{$\begin{array}{l}0.3 \\
0.5\end{array}$} \\
\hline Maknung- Wang $\mathrm{An}$ & 13 & \\
\hline Warts An-Chilstej & 12 & 0.5 \\
\hline Tuipej-Muliu & 31 & 1,2 \\
\hline 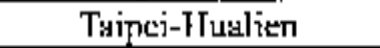 & 59 & 2,3 \\
\hline Hualien-Grecen Telland & 67 & 2.6 \\
\hline laitung (Grecn Island & 80 & 3 \\
\hline Kanblitung-(ivent lslatd & 31 & 1.2 \\
\hline Tuilumy- & 14 & 0.6 \\
\hline tolal & 2590 & 100 \\
\hline
\end{tabular}

1: The airpolts over the esstem eosst of Tuiwun 
over a large zonal range over the Taipei FIR (same for Fig. 9). The $\mathrm{O}_{3}$ concentrations reach a minimum just east of the flight corridor where the concentrations decrease by a few ppt. The $\mathrm{O}_{3}$ depletion then gradually diminishes downwind, with a more obvious depletion toward the east than the west due to the asymmetrical wind probability. As discussed in Fig. 2, the $\mathrm{O}_{3}$ perturbation is mostly negative during the first day, and it usually takes less than a day for plume to travel across the domain. Therefore, the $\mathrm{O}_{3}$ perturbation is mostly negative to the east of the flight corridor. Positive $\mathrm{O}_{3}$ perturbations may only occur at a distance much further downwind. The easterlies are normally weaker (negative wind speed in Fig. 7), resulting in a slower movement of aircraft plume toward the west. Within such a time frame, the $\mathrm{O}_{3}$ concentration in the aircraft plume may become greater than in the ambient air not far to the west of the flight corridors. Figure 8a shows a more gradual change of $\mathrm{O}_{3}$ concentration with distance than in Fig. $8 \mathrm{~b}$ because the aircraft plume expands more slowly in the upper troposphere as discussed before.

Figures $9 \mathrm{a}$ and $9 \mathrm{~b}$ show the spatial variations of sulfate perturbations at the international and domestic flight corridors. Due to the complex distribution of wind speed probability, the sulfate perturbations are also rather asymmetrical about the flight corridor. To the west of the flight corridor, the sulfate enhancement are smaller, mainly because of the low probability of easterly winds. To the east, the sulfate enhancement remain above $10^{-3}$ to $10^{-4} \mathrm{ppt}$ at the international and domestic corridors. The peak sulfate concentration just east of the flight corridor results from the sulfate production through reaction of $\mathrm{HO}$ and $\mathrm{SO}_{2}$ during the first day, corresponding to the time variation of sulfate concentrations shown in Fig. 6. Westerlies are usually stronger at $11 \mathrm{~km}$ than at $6 \mathrm{~km}$, therefore the peak sulfate concentration occurs slightly farther downwind at the international flight altitudes (Fig. 9a) than at the domestic flight altitudes as shown in Fig. 9b.

\subsection{Spatial Variations over the Taipei FIR}

The regional impacts of aircraft emissions at the international and domestic flight altitudes over the Taipei FIR were composed after multiplying the plume results with flight frequencies and overlay onto each flight route. Figure 10a shows the perturbation of $\mathrm{O}_{3}$ concentrations at the international flight altitudes (about $11.5 \mathrm{~km}$ ). The most significant (negative) $\mathrm{O}_{3}$ perturbations occur along the ELA-APU-BLN flight corridor (called Route A1 hereafter). Under the dominant westerly winds, all regions east of Route $\mathrm{A} 1$ experience $\mathrm{O}_{3}$ reduction by more than $0.1 \mathrm{ppb}$, with a maximum reduction of more than $0.3 \mathrm{ppb}$ occurring near the junction points APU (at the northern tip of Taiwan) and HCN (at the southern tip of Taiwan) due to the maximum overlapping of aircraft plumes. The background $\mathrm{O}_{3}$ concentration is about 41 ppb (see Fig. 2a), and thus the aircraft emissions resulted in less than $1 \%$ reduction in $\mathrm{O}_{3}$ concentration eastward of Route A1. From Route A1 to the east coast of China, $\mathrm{O}_{3}$ concentrations increase and become slightly higher than in the background because the longer traveling time of the aircraft plume under the weak easterlies allows $\mathrm{O}_{3}$ production.

Figure $10 \mathrm{~b}$ shows the perturbation of $\mathrm{O}_{3}$ concentrations at the domestic flight altitudes (about $6.5 \mathrm{~km}$ ). The most significant reduction occurs along the western coast of Taiwan, with a maximum reduction over $1.6 \mathrm{ppb}$. Most other areas around the main domestic flight corridor 
(a)

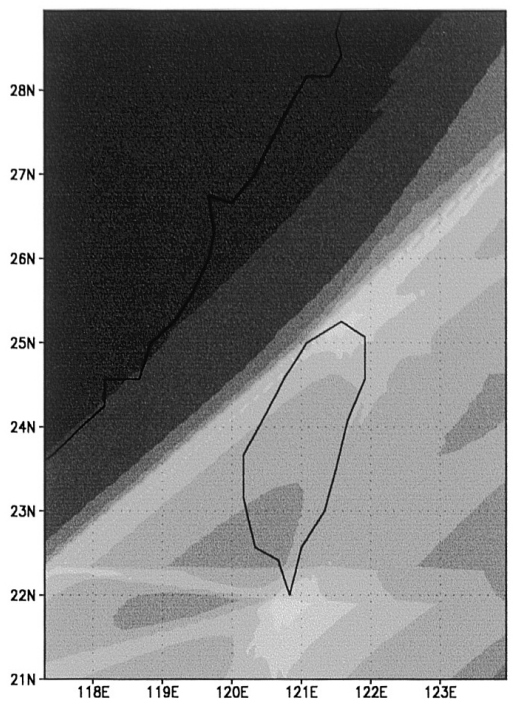

(b)

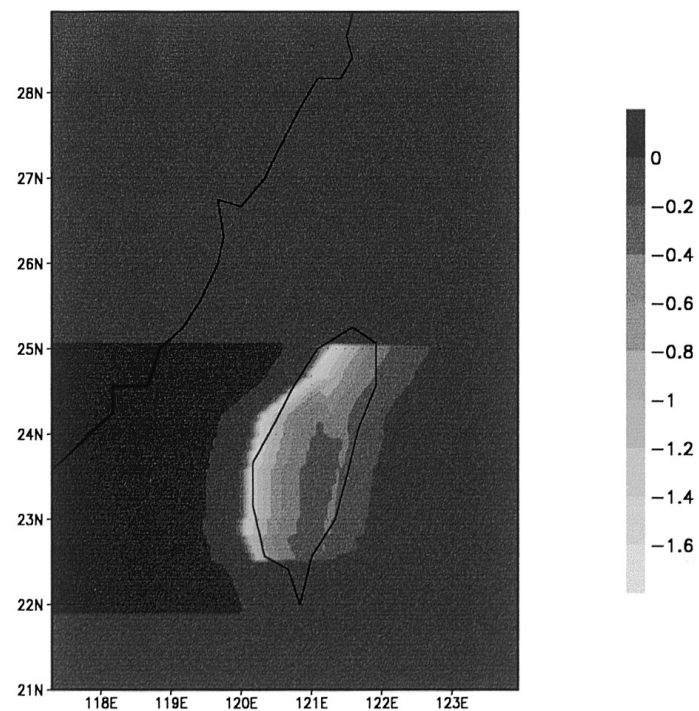

Fig. 10. Aircraft induced perturbations of $\mathrm{O}_{3}$ concentration (ppb) at the (a) international and (b) domestic flight altitudes over the Taipei Flight Information Region.

experience $\mathrm{O}_{3}$ reduction by more than $1 \mathrm{ppb}$. Comparing to the background concentration of about $36 \mathrm{ppb}$ (see Fig. 2b), the maximum reduction percentage is about $4 \%$. The reduction ratios are higher than those in the international corridors, mainly due to the much higher flight frequencies and more concentrated flight zones. To the west of the western coast, the $\mathrm{O}_{3}$ concentration is enhanced, but the perturbations are small, due to a low probability of easterly winds at these altitudes.

Figure 11 shows the $\mathrm{O}_{3}$ change in the whole column of the troposphere due to international and domestic aircraft emissions. The unit of the column $\mathrm{O}_{3}$ change is converted into mixing ratio by assuming the tropopause height of $15 \mathrm{~km}$, and calculating the mole fraction of the $\mathrm{O}_{3}$ perturbation relative to the whole air column of the troposphere. In contrast to the concentration change at the flight altitudes, which is reduced due to aircraft emissions, the column $\mathrm{O}_{3}$ change is actually enhanced. The mean enhancement of column $\mathrm{O}_{3}$ due to international flights (Fig. 11a) is about $12 \mathrm{ppt}$ and may reach $16 \mathrm{ppt}$ near the southwestern border of the Taiwan areas. The enhancement of column $\mathrm{O}_{3}$ mass due to domestic flights is much more significant (Fig. 11b), with values mostly over $0.3 \mathrm{ppb}$ within the latitudinal extent of the Taipei FIR. The reversal of sign between the concentration change and the column change is due to overlapping of aircraft plumes with different ages within the domain. According to the probability distribution of the zonal wind frequencies shown in Fig. 7, aircraft plumes emitted at the flight altitudes can be transported by various wind speeds. The aircraft plumes transported by weak winds tend to be more aged (still quite different than the ambient air) in the 
(a)

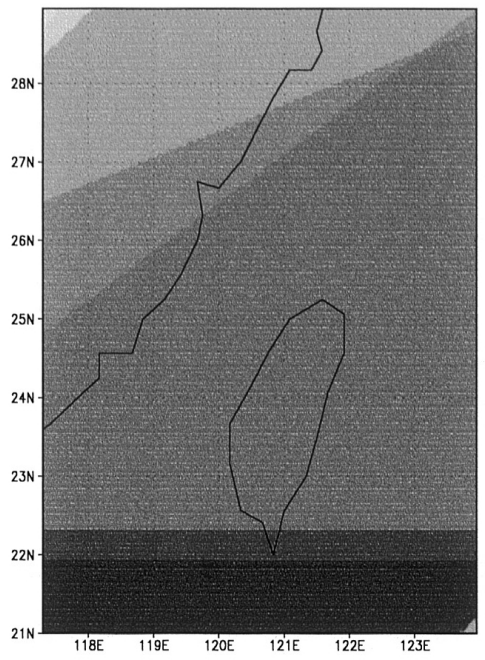

(b)

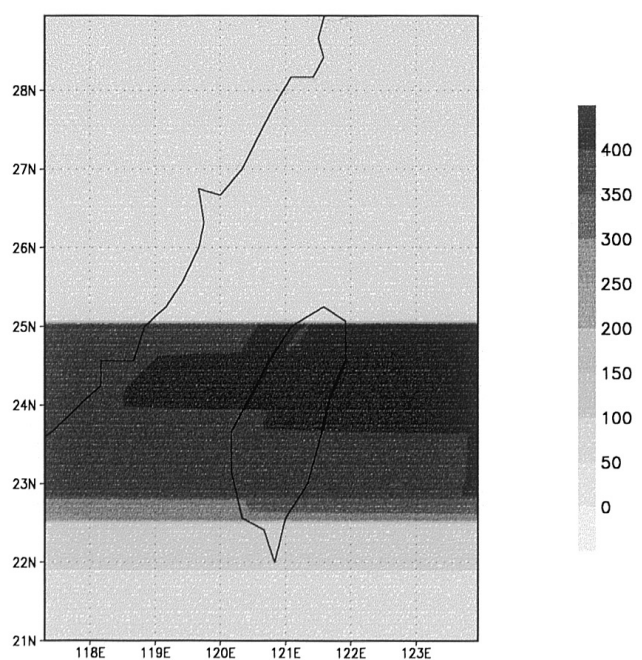

Fig. 11. Aircraft induced perturbations of column $\mathrm{O}_{3}$ change (ppt) from the (a) international and (b) domestic flights over the Taipei Flight Information Region.

domain, occupying greater volume and containing higher $\mathrm{O}_{3}$ concentration. Since the column $\mathrm{O}_{3}$ change is proportional to the plume volume in the domain, these aged plumes are heavily weighted in the calculation of column $\mathrm{O}_{3}$ change even though their probability is much lower. Thus the total column $\mathrm{O}_{3}$ change calculated from these much bigger plumes with enhanced $\mathrm{O}_{3}$ concentrations outweighs the $\mathrm{O}_{3}$ loss from those smaller plumes; whereas in calculating the concentration change at the flight altitudes, these bigger plumes with diluted concentrations are less weighted than the smaller plumes with concentrated pollutants. The column $\mathrm{O}_{3}$ enhancement is more obvious due to the domestic aircraft emissions than the international aircraft emissions mainly because of the weaker winds and thus longer plume residence time at the altitudes.

The perturbations of sulfate concentration at the flight altitudes are shown in Fig. 12. The sulfate perturbation at the international flight altitudes (Fig. 12a) is minimal at the northwest corner and increases toward the southeast of the domain, with a maximum perturbation reaching about $0.16 \mathrm{ppt}$. The sulfate perturbation is more obvious near the south border of the domain because the eastward drifting plumes emitted near the southwestern border have the longest time for sulfate production within the domain. Figure $12 \mathrm{~b}$ shows the sulfate perturbations at the domestic flight altitudes. The production of sulfate concentrated at and to the east of the main flight corridors along the western coast of Taiwan, reaching a maximum of about $0.35 \mathrm{ppt}$, and decrease with distance away from the corridors as aircraft plumes quickly diluted under strong vertical diffusion rate. The decrease with distance is more dramatic over the western side of the main flight corridor due to a lower probability of the easterlies. Relative to the background gas-phase sulfate concentration of usually less than several ppt, the 
(a)

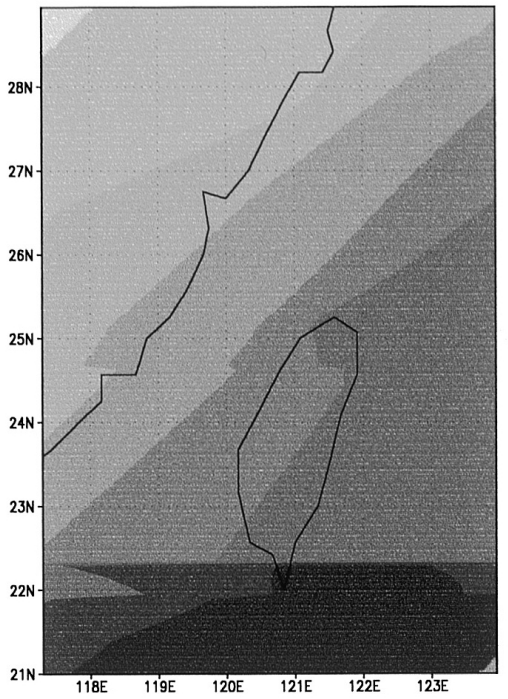

(b)

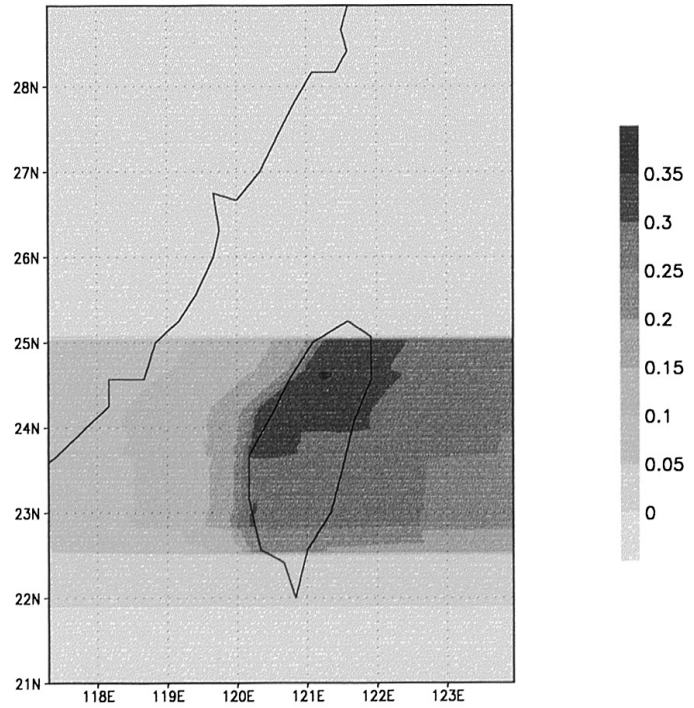

Fig. 12. Same as in Fig. 9, but for perturbation of sulfate concentrations (ppt) at the (a) international and (b) domestic flight altitudes.

sulfate perturbations shown in Fig. 12 are supposed to be rather substantial. But, because the produced sulfate mostly transforms into sulfate particles, the perturbations to the ambient sulfate aerosol concentration are less than several percent.

Figures 13a and $13 \mathrm{~b}$ show the perturbations of the column sulfate due to the international and domestic aircraft emissions, respectively. Similar to those shown in Fig. 12a, the maximum sulfate enhancement due to international flights is near the southern border of the Taipei FIR where maximum overlapping of the aged aircraft plumes occurs. Most of the enhancement over the Taiwan area is about $0.05 \mathrm{ppt}$ due to international aircraft emissions. The sulfate perturbation due to domestic aircraft emissions, on the other hand, is mostly negative. The perturbations range from 0 to -2 ppt within the latitudinal extent of the Taipei FIR. As discussed earlier for column $\mathrm{O}_{3}$, weaker winds allow aircraft plumes to stay longer and grow bigger in the domain, and therefore these plumes contribute more significantly to the column perturbations. Since the sulfate concentrations within the aircraft plumes are slightly lower than in the ambient air several days after the emission (see Fig. 6b), the overall change of column sulfate turns out to be negative due to domestic flights. The perturbation of column sulfate is about -1.6 ppt over most of the Taipei FIR. Relative to the background aerosol sulfate concentration of about 15 to $30 \mathrm{ppt}$ in most of the troposphere (Thornton et al. 1996), the perturbation is about 5 to 10 percents.

\section{DISCUSSIONS AND CONCLUSIONS}

This study applied a Lagrangian plume-scale model to simulate the temporal variation of 
(a)

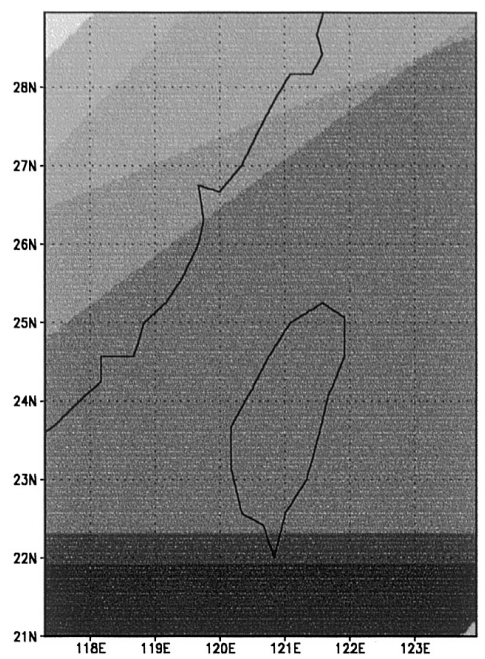

(b)

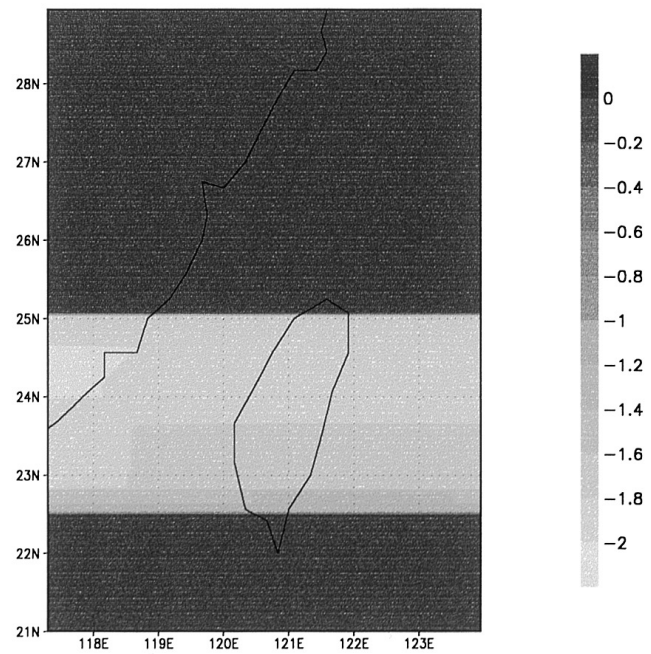

Fig. 13. Same as in Fig. 10, but for the column sulfate change (ppt) due to the (a) international and (b) domestic flights over the Taipei Flight Information Region.

chemistry in aircraft plumes, which expand with time by mixing in the ambient air while being advected downwind. The aircraft-induced perturbations of $\mathrm{O}_{3}$ and sulfate concentrations calculated from the plume model were then composed into a regional distribution over the Taipei FIR by including the flight frequencies and the wind speed probability at the international and domestic flight corridors. The results of the Lagrangian plume model indicate that the $\mathrm{O}_{3}$ concentrations within the aircraft plume can be substantially reduced within the first day after emissions due to reaction with high concentration of NO emitted by the aircraft. The maximum concentration reduction in a plume may reach over $15 \mathrm{ppb}$ at both the international and domestic flight altitudes. After about 1 day when ambient air with higher $\mathrm{O}_{3}$ concentration and lower $\mathrm{NO}_{x}$ concentration mixes in, $\mathrm{O}_{3}$ concentration in the aircraft plume gradually increases to the ambient level. As aircraft plumes move further downwind, $\mathrm{O}_{3}$ in the plume is produced by $\mathrm{NO}_{x}$-related reactions and becomes higher than in the ambient air. Although the concentration of $\mathrm{NO}_{x}$ and other emitted chemicals quickly decreases with time due to chemical conversions as well as plume dilution, $\mathrm{O}_{3}$ is continuously generated through $\mathrm{NO}_{\mathrm{x}}$ related reactions as long as the emitted $\mathrm{NO}_{\mathrm{x}}$ molecules remain in the air.

When considering the impacts due to all aircraft emissions over the Taiwan area, the maximum reduction of $\mathrm{O}_{3}$ concentration reaches about 1 to $4 \%$ at about 11.5 and $6.5 \mathrm{~km}$ of the international and domestic flight altitudes, respectively. The results of calculated $\mathrm{O}_{3}$ perturbations in this study are quite different than those in previous studies (Brasseur et al. 1996; Johnson and Stevenson 1996; Schumann 1997) in which aircraft induced perturbations were positive and the values could be as large as 1 to $10 \%$ relative to the background concentrations 
at the northern mid-latitude upper troposphere. Negative $\mathrm{O}_{3}$ perturbations were obtained over the Taipei FIR because the mean residence time of air in the domain is about several hours to half a day. Within this limited time frame, $\mathrm{O}_{3}$ is locally reduced by the high concentration of $\mathrm{NO}$ emitted by the aircraft. As indicated by the Lagrangian plume model, net $\mathrm{O}_{3}$ production can only occur about half or one day after the emissions, by which time the aircraft plume usually has already been advected out of the domain by the strong westerly wind.

The perturbation of tropospheric column $\mathrm{O}_{3}$, on the other hand, is enhanced by the aircraft emissions. The total enhancement of column $\mathrm{O}_{3}$ can reach $16 \mathrm{ppt}$ and $0.4 \mathrm{ppb}$ due to the international and domestic aircraft emissions, respectively. The reversal of sign between the perturbation of layered $\mathrm{O}_{3}$ concentration and the column $\mathrm{O}_{3}$ mass is a result of different volume weighting between young and aged plumes. Aircraft plumes transported by weaker wind speed have longer residence time and higher volume expansion ratio in the Taipei FIR, and these aged plumes have more time to generate $\mathrm{O}_{3}$ through $\mathrm{NO}_{x}$ related reactions. Thus the overall $\mathrm{O}_{3}$ productions in these bigger plumes outweigh those from the younger and smaller plumes. Thus, although aircraft emissions may locally reduce $\mathrm{O}_{3}$ concentration at the flight altitudes, the total $\mathrm{O}_{3}$ mass is enhanced in the troposphere.

The sulfate concentrations were enhanced at the flight altitudes due to aircraft emission of $\mathrm{SO}_{2}$, which reacts with $\mathrm{OH}$ radical to form sulfate. Within aircraft plumes, the sulfate concentrations can be enhanced by up to several to over $10 \mathrm{ppt}$ depending on the flight altitudes. In the upper troposphere, the sulfate is continuously generated during the simulation, with peak sulfate enhancement occurring during the first three days after emissions. Schumann et al. (1996) estimated that gas phase sulfate was enhanced by about 4 to $140 \mathrm{ppt}$ within an aircraft plume depending on the sulfur content in the fuel, and our results of peak sulfate enhancement fall within this range. In the domestic flight altitudes, the plume is diluted rather quickly because of the faster expanding of the plume size compared to those in the international flight altitudes, so the sulfate enhancement inside is less obvious. The sulfate concentrations even became lower than in the ambient air several days after emission as the plume $\mathrm{HO}$ concentration became lower by reacting with other exhaust chemicals.

At both the international and domestic flight altitudes over the Taiwan areas, the enhancement in sulfate concentration is less than 0.2 and 0.4 ppt. The perturbations of column sulfate are about $0.05 \mathrm{ppt}$ due to the international aircraft emissions, and about $-1.6 \mathrm{ppt}$ due to the domestic aircraft emissions over most of the Taiwan areas. Again, these column perturbations result from the overlapping of plumes of different sizes and ages. As aircraft plume evolves with time at the domestic flight altitudes, the sulfate concentration within the aircraft plume can be slightly lower than in the ambient air due to the depletion of $\mathrm{SO}_{2}$ and $\mathrm{OH}$. These welldiluted plumes with negative sulfate perturbations dominate the total column sulfate production, resulting in negative column sulfate perturbations over the Taipei FIR. The gas-phase sulfate concentration in the background atmosphere is usually very low, with values of about $10^{-2}$ to a few ppt in the free troposphere (Möhler and Arnold 1992). Mostly likely the sulfate produced will convert into sulfate aerosol and be sources of condensation nuclei (Schumann et al. 1996; Thornton et al. 1996). Relative to the background sulfate aerosol concentration, the sulfate perturbations are less than 1 or 2 percent at the flight altitudes and less than 1 to $10 \%$ in the troposphere due to aircraft emission of $\mathrm{SO}_{2}$. This study also indicated that aircraft emissions 
may either increase or decrease sulfate mass in troposphere depending on the emitted altitudes.

This study shows that the impacts of the domestic aircraft emissions and the international aircraft emissions are quite different. The impacts are larger for domestic aircraft emissions over the Taiwan areas, mainly because the flight frequencies of the domestic flights are more than 4 times greater than those of the international flights. This study also shows that the perturbations of the $\mathrm{O}_{3}$ and sulfate concentrations are more localized in the domestic flight altitudes than in the international flight altitudes. This is because the vertical expansion of the aircraft plumes is much stronger in the domestic flight altitudes, resulting in a quick dilution of aircraft plumes before they are transported further downwind; whereas the aircraft plumes can remain more concentrated over a longer distance in the international flight altitudes and the aircraft impacts on the $\mathrm{O}_{3}$ and sulfate concentrations will extend over a much broader area. On the other hand, the impacts on column $\mathrm{O}_{3}$ and sulfate will be smaller under a smaller diffusion rate because the volumes of the aircraft plumes are smaller within the domain.

In this study, we applied the chemical concentrations observed over the western Pacific Ocean or the typical background atmosphere as the initial ambient concentrations. Since some chemical concentrations, such as $\mathrm{NO}_{\mathrm{x}}$, are subjected to large temporal and spatial variations, their measured ambient concentrations also vary with time and area, and thus the results obtained in this study can also change. A further sensitivity study indicated that the results of $\mathrm{O}_{3}$ and $\mathrm{SO}_{2}$ perturbations due to aircraft emissions calculated in this study remained only slightly changed by changing the initial ambient $\mathrm{NO}_{\mathrm{x}}$ concentrations from about 40 to $200 \mathrm{ppt}$ at the international flight altitudes or 30 to $90 \mathrm{ppt}$ at the domestic flight altitudes. The sulfate perturbations, however, can range by $50 \%$ and $10 \%$ at the international and domestic flight altitudes, respectively, due to changing the initial ambient $\mathrm{NO}_{\mathrm{x}}$ concentrations. Therefore, since some results can be sensitive to the ambient conditions chosen, it is necessary to apply ambient conditions representative of the real atmospheric conditions in calculating aircraft induced perturbations.

In calculating $\mathrm{O}_{3}$ perturbations due to aircraft emissions, large-scale modeling studies usually assume that aircraft emissions are instantly diluted into the model grid. Since $\mathrm{O}_{3}$ production rate exhibits a nonlinear relationship with $\mathrm{NO}_{\mathrm{x}}$ and hydrocarbon concentrations, an artificial dilution of aircraft emissions can result in large errors in calculating $\mathrm{O}_{3}$ concentration (Petry 1999; Tsai and Walcek 2001). This study avoided such a problem by explicitly calculating the $\mathrm{O}_{3}$ perturbation within each aircraft plume without the artificial dilution effect. Then, the overall annual mean $\mathrm{O}_{3}$ perturbations over the Taipei FIR were estimated by linearly summing up the effects from all flights. The linear mapping method is applicable in this study because the plumes from different aircraft hardly cross each other to induce nonlinear computation error. By applying larger scale models in which the nonlinear plume-scale reactions can not be resolved, the calculated aircraft induced $\mathrm{O}_{3}$ perturbations are usually positive (Tsai 1999; Ma 2000), while the actual $\mathrm{O}_{3}$ perturbations can be negative over local areas. Our composite results provide a method for more accurately calculating the $\mathrm{O}_{3}$ perturbation due to aircraft emissions over a relatively short time period or small model domains, such as the Taiwan area.

Under strong westerlies at the flight altitudes, the impacts of aircraft emissions over certain areas are attributed to not only in situ flights but also flights at any upwind area or even 
downwind area if the pollutants could travel around the globe. As $\mathrm{O}_{3}$ is continuously generated from $\mathrm{NO}_{x}$ emissions while transported downwind, and the lifetimes of $\mathrm{NO}_{x}$ and $\mathrm{O}_{3}$ are usually several days or longer in the upper troposphere, the emissions from other regions of the world could offset the $\mathrm{O}_{3}$ perturbations estimated in our model domain. However, in the present study, only the emission impacts from the estimated Taiwan aircraft were considered. The net effect with consideration of emissions from other aircraft corridors still requires more extensive investigation.

Acknowledgments This research was supported by the National Science Council under Grants NSC-87-2621-P-002-002 and NSC-88-2111-M-002-016.

\section{REFERENCES}

Anderson, B. E., J. Hallett, K.-N. Liou, K. Sassen, H. B. Singh, and L. R. Williams, 1997: Understanding the effects of aircraft emissions. In: R. R. Friedl (Ed.), Atmospheric Effects of Subsonic Aircraft: Interim Assessment Report of the Advanced Subsonic Technology Program. NASA Reference Publication 1400, NASA Headquarters, Washington, D. C., 27-56.

Arnold, F., R. Fabian, and W. Joos, 1981: Measurements of the height variation of sulfuric acid vapor concentrations in the stratosphere. Geophys. Res. Lett., 8, 293-296.

Beck, J. P., C. E. Reeves, F. A. A. M. de Leeuw, and S. A. Penkett, 1990: The Effect of Aircraft Emissions on Atmospheric Ozone in the Northern Hemisphere. Report nr. 222201001, National Institute of Public Health and Environmental Protection, Bilthoven, the Netherlands and School of Environmental Sciences, University of East Anglia, Norwich, United Kingdom.

Brasseur, G. P., J. Muller, and C. Granier, 1996: Atmospheric impacts of $\mathrm{NO}_{\mathrm{x}}$ emissions by subsonic aircraft: A three-dimensional model study. J. Geophys. Res., 101, 1423-1428.

Charlson, R. J., S. E. Schwartz, J. M. Hales, R. D. Cess, J. A. Coakley Jr., J. E. Hansen, and D. J. Hoffman, 1992: Climate forcing by anthropogenic aerosols. Science, 255, 423-430.

Chen, J.-P., W.-H. Lin and R.-F. Lin, 2001: Estimation of contrail frequency and radiative effects over the Taiwan areas. TAO, 12, 155-178.

Cuong, Nguyen Ba, Bernard Bonsang, and Gerard Lambert, 1974: The atmospheric concentration of sulfure dioxide and sulfate aerosols over antarctic, subantarctic areas and oceans. Tellus, 26, 241-249.

Ellingson, R. G., J. Ellis, and S. Fels, 1991: The intercomparison of radiation codes used in climate models: long wave results. J. Geophys. Res., 96, 8929-8953.

Ford, I. J., G. D. Hayman, and R. D. Kingdom, 1996: Plume and aerosol modeling for the POLINAT project. In: U. Schumann (Eds.), Pollution from Aircraft Emissions in the North Altantic Flight Corridor (POLINAT), Air Pollution Research Report 58, European Commission, 258-279.

Georgii, H.-W., 1978: Large scale spatial and temporal distribution of sulfur compounds. Atmos. Environ, 12, 681-690.

Hagen, D. E., P.D. Whitefield, and H. Schlager, 1996: Particulate emissions in the exhaust 
plume from commercial jet aircraft under cruise conditions. J. Geophys. Res., 101, 19, 551-19,557.

Hanna, S. R., G. A. Briggs, and R. P. Hosker, Jr., 1982: Handbook on Atmospheric Diffusion, Published by Technical Information Center. U. S. Department of Energy, Washington, DC.

Hoshizaki, H., 1975: Aircraft wake microscale phenomena. In CIAP Monograph, Vol. 3, Climatic Impact Assessment Program, U.S. Dep. of Transp., Washington, D. C., 6073.

Hayman, G. D., and M. Markiewicz, 1996: Chemical Modelling of the Aircraft Exhaust Plume. In: U. Schumann (Eds.), Pollution from Aircraft Emissions in the North Altantic Flight Corridor (POLINAT), Air Pollution Research Report 58, European Commission, 280303.

IPCC, 1999: Aviation and the Global Atmospheric. In: J. E. Penner, D. H. Lister, D. J. Griggs, D. J. Dokken, and M. Mcfarland (Eds.), Cambridge University Press, p.373.

Johnson, C. E., and D. S. Stevenson, 1996: Effect on tropospheric oxidant concentrations resulting from aircraft $\mathrm{NO}_{x}$ emissions. In: U. Schumann (Eds.), Pollution from Aircraft Emissions in the North Altantic Flight Corridor (POLINAT), Air Pollution Research Report 58, European Commission, 175-202.

Kärcher, B., 1995a: A trajectory box model for aircraft exhaust plumes. J. Geophys. Res., 100, 18835-18844.

Kärcher, B., T. Peter, and R. Ottmann, 1995b: Contrail formation: Homogeneous nucleation of $\mathrm{H}_{2} \mathrm{SO}_{4} / \mathrm{H}_{2} \mathrm{O}$ droplets. Geophys. Res. Lett., 22, 1501-1504.

Kärcher B., M.M. Hirschberg, and P. Fabian, 1996: Small-scale chemical evolution of aircraft exhaust species at cruising altitudes. J. Geophys. Res., 101, 15169-15190.

Kasibhatla, P. S., 1993: $\mathrm{NO}_{\mathrm{y}}$ from sub-sonic aircraft emissions: A global three-dimensional model study. Geophys. Res. Lett., 20, 1707-1710.

Lin, P.-H., W.-S. Sun, and J.-P. Chen, 2001: Emission Inventory of Civil Aircraft over Taiwan, $T A O, 12,41-62$.

Liu, S. C., J. R. McAfee, and R. J. Cicerone, 1984: Radon 222 and Tropospheric Vertical Transport. J. Geophys. Res., 89, 7291-7297.

Ma, J. 2000: Development of a three-dimensional inventory of aircraft $\mathrm{NO}_{\mathrm{x}}$ emissions over China. Atmos. Environ., 34, 389-396.

Meijer, E. W., P. F. J. van Velthoven, A. M. Thompson, L. Pfister, H. Schlager, P. Schulte, and $\mathrm{H}$. Kelder, 2000: Model calculations of the impacts of $\mathrm{NO}_{\mathrm{x}}$ from air traffic, lightning, and surface emissions, compared with measurements. J. Geophys. Res., 105, 38333850 .

Möhler, O., and F. Arnold, 1992: Gaseous sulfuric acid and sulfur dioxide measurements in the arctic troposphere and lower stratosphere: Implication for hydroxyl radical abundances. Geophys. Res. Lett., 19, 1763-1766.

Petry, H. J. Hendricks, M. Mollhoff, E. Lippert, A. Meier, and A. Ebel, 1998: Chemical conversion of subsonic aircraft emissions in the dispersing plume: Calculation of effective emission indices. J. Geophys. Res., 103, 5759-5772.

Pitari, G., V. Rizi, L. Ricciardulli, and G. Visconti, 1993: High-Speed Civil Transport Impact: 
Role of Sulfate, Nitric Acid Trihudrate, and Ice Aerosols Studied With a Two-Dimensional Model Including Aerosol Physics. J. Geophys. Res., 98, 23,141-23,164.

Schumann, U., P. Konopka, R. Baumann, R. Busen, T. Gerz, H. Schlager, P. Schulte, and H. Volkert, 1995: Estimate of Diffusion Parameters of Aircraft Exhaust Plumes Near the Tropopause from Nitric Oxide and Turbulence Measurements. J. Geophy. Res., 100, $14,147-14,162$.

Schumann, U., J. Strom, R. Busen, R. Baumann, K. Gierens, M. Krautstrunk, F. P. Schroder, and J. Stingl, 1996: In situ observations of particles in jet aircraft exhausts and contrails for different sulfur-containing fuels. J. Geophys. Res., 101, 6853-6869.

Schumann, U., 1997: The impact of nitrogen oxides emissions from aircraft upon the atmosphere at flight altitudes - Results from the Aeronox project. Atmos. Environ., 31, 17231733.

Simpson, I. J., T.-Y. Chen, D. R. Blake, and F. S. Rowland, 2000: Recent Changes in the Growth Rate of Tropospheric Methane. Summitted to Geophys. Res. Lett.

Singh, H. B., D. Herlth, R. Kolyer, L. Salas, J. D. Bradshaw, S. T. Sandholm, D. D. Davis, J. Crawford, Y. Kondo, M. Koike, R. Talbot, G. L. Greygory, G. W. Sachse, E. Browell, D. R. Blake, F. S. Rowland, R. Newell, J. Merill, B. Heikes, S. C. Liu, P. J. Crutzen, and M. Kanakidou, 1996: Reactive nitrogen and ozone over the western Pacific: Distribution, Partitioning, and sources. J. Geophy. Res., 101, 1793-1808.

Stockwell, W. R., P. Middleton, and J. S. Chang, 1990: The Second Generation Regional Acid Deposition Model Chemical Mechanism for Regional Air Quality Modeling. J. Geophys. Res., 95, 16343-16367,.

Talbot, R. W., J. E. Dibb, K. I. Klemm, J. D. Bradshaw, S. T. Sandholm, D. R. Blake, G. W. Sachse, J. Collins, B. G. Heikes, G. L. Gregory, B. E. Anderson, H. B. Singh, D. C. Thornton, and J. T. Merrill, 1996: Chemical characteristics of continental outflow from Asia to the troposphere over the western Pacific Ocean during September-October 1991: Results from PEM-West A. J. Geophys. Res. 101, 1713-1725.

Thornton, D. C., A. R. Bandy, B. W. Blomquist, D. D. Davis, and R. W. Talbot, 1996: Sulfur dioxide as a source of condensation nuclei in the upper troposphere of the Pacific Ocean. J. Geophys. Res. 101, 1883-1890.

Tsai, F., 1999: Plume-scale and regional-scale modeling studies of uncertainties associated with calculated impacts of aircraft emissions on upper tropospheric $\mathrm{O}_{3}$. Ph.D. dissertation, State University of New York, Albany, NY, 191.

Tsai, F., and C. J. Walcek, Estimating chemical errors in large-scale simulations of aircraft emissions. TAO, 12, 79-108.

Yu, F., and R. P. Turco, 1997: The role of ions in the formation and evolution of particles in aircraft plumes. Geophys. Res. Lett., 24, 1927-1930.

Zhao, J., and R. P. Turco, 1995: Nucleation simulations in the wake of a jet aircraft in stratospheric flight. J. Aerosol Sci., 26, 779-795. 